J. Lake Sci. (湖泊科学), 2011, 23(4):520-526

http: //www.jlakes.org. E-mail : jlakes@niglas.ac.cn

(c) 2011 by Journal of Lake Sciences

\title{
路径分析法在滇池流域水污染防治规划中的应用”
}

\author{
邓义祥 ${ }^{1}$, 郑一新 ${ }^{2}$, 富 国 $^{1}$, 雷 坤 $^{1}$, 刘瑞志 ${ }^{1}$, 张林波 $^{1}$, 李子成 ${ }^{1}$ \\ (1: 中国环境科学研究院, 北京 100012 ) \\ (2: 昆明市环境科学研究院, 昆明 650031$)$
}

\begin{abstract}
摘 要: 在基于负荷总量的水污染防治规划中, 通常需要在特定的水质目标条件下, 核定污染物的最大允许排放量和削 减量, 并采取工程措施完成削减目标. 路径分析法将正向算法中的污染控制参数由连续变量进行离散化, 既对优化问题 进行了简化, 也提高了优化方案的针对性和可行性. 以滇池流域水污染防治规划为例, 采用路径分析方法, 将滇池流域水 污染控制六大措施的参数离散化, 寻找不同目标方案条件下滇池流域污染治理的最佳方案. 在此基础上, 结合滇池流域 水污染治理的实际,推荐中方案为“十二五”规划的目标,并提出了对应的污染物总量削减措施.
\end{abstract}

关键词: 路径分析;滇池流域;水污染防治规划;“十二五”规划

\section{Application of route analysis method in the water pollution control planning in Lake Dian- chi Catchment}

\author{
DENG Yixiang ${ }^{1}$, ZHENG Yixin $^{2}$, FU Guo ${ }^{1}$, LEI Kun ${ }^{1}$, LIU Ruizhi ${ }^{1}$, ZHANG Linbo $^{1} \&$ LI Zicheng ${ }^{1}$ \\ (1: Chinese Research Academy of Environmental Sciences, Beijing 100012, P. R. China) \\ (2: Kunming Institute of Environmental Sciences, Kunming 650031, P. R. China)
}

\begin{abstract}
In water pollution control planning based on total waste load, it is usually necessary to check the total maximum allowable load and choose proper countermeasures to finish the load cut task under specified water quality objectives. With the route analysis method, the continuous control variables in the direct algorithm are discretized, so not only the optimization problem is simplified, but also the result is more practicable and pertinent. Take the Lake Dianchi Catchment as an example, the 6 water pollution control measures were discretized by parameters and the most suitable pollution control schemes were selected under different water quality scenarios with route analysis method. Afterwards, based on the historical and present treatment situation in the study area, the medium-scenario and corresponding countermeasures were suggested for the $12^{\text {th }}$ Five-Year Water Pollution Control Planning in the Dianchi Cactchment.
\end{abstract}

Keywords: Route analysis; Lake Dianchi Catchment; water pollution control planning; $12^{\text {th }}$ Five-Year Plan

水污染防治规划是进行水污染治理的重要依据, 在我国水环境管理中具有越来越重要的地位.工程措 施的目标可达性是制订水污染防治规划的重要内容. 在核定的污染物削减目标条件下, 确定水环境治理的 任务和措施, 实际上是一个具有约束条件的优化问题, 也就是说, 以工程措施的各项参数为优化变量, 以实 现预定的削减总量为目标, 寻求治理成本最低的污染控制方案 ${ }^{[1]}$. 传统的污染物总量分配根据等比例分配、 最小处理费用、按污染程度削减排放量以及考虑公平性的基尼系数分配等原则方法, 采用反算的方式, 确定 各污染源的分配总量和削减量 ${ }^{[2-4]}$. 但如果忽略控制区域的具体条件和可行性因素, 仅仅采用各种数学方法 进行控制参数优化而得到一套污染控制方案,将有可能面临可行性不足的问题.

规划实践表明,水污染控制措施的情景往往是有限的. 例如污水处理厂出水浓度的约束,往往有“保持 现状、达到一级 B 标、达到一级 $A$ 标、达到地表水 $V$ 类标准、达到地表水 $I V$ 类标准” 等预期目标, 这时过分强 调污水浓度值变化的连续性意义往往不大. 同样其它的工程措施能得到人们普遍理解和认同往往也是有限

* 滇池流域水污染防治 “十二五” 规划项目资助. 2010-09-28 收稿;2010-12-21 收修改稿. 邓义祥, 男, 1974 年生, 博士,副研究员; E-mail: dengyixiang@ gmail. com. 
的几种情景. 因此,基于正向计算的思路,分析各类污染源可能的削减途径, 寻求污染物总量达标的方案, 将 最大限度地体现管理者的污染控制思路. 采用路径分析方法, 将正向算法中工程措施参数的连续优化问题 转化为离散优化问题, 寻找到能够完成规划目标可能的路径,再通过协商和综合分析, 确定最后的推荐方 案, 不仅使优化问题的复杂性大大降低, 也增加了规划方案的可操作性. 本文以滇池流域水污染防治规划为 例,采用路径分析方法,提出滇池水污染治理的推荐方案.

\section{1 研究区域和研究方法}

\section{1 研究区域}

滇池流域是云南省政治、经济、文化中心和交通枢纽, 是昆明市人口最密集、人类活动最频繁、经济最发 达的地区. “十一五” 期间, 滇池流域人口继续保持稳定增长, 常住人口 2008 年底达到 $340.7 \times 10^{4}$ 人, 其中非 农业人口 $264.0 \times 10^{4}$ 人, 农业人口 $76.7 \times 10^{4}$ 人. 滇池流域经济发展迅速, 综合实力不断增强. 2008 年滇池 流域国内生产总值达到 $1280 \times 10^{8}$ 元, 约占昆明市的 $80 \%$, 第一、二、三产业结构为 2.6:43.7:53.7, 人均 GDP 为 $3.76 \times 10^{4}$ 元, 相当于我国中等发达地区的水平.

滇池是高原浅水型湖泊, 是我国第六大淡水湖. 滇池流域面积 $2920 \mathrm{~km}^{2}$, 总库容 $12.9 \times 10^{8} \mathrm{~m}^{3}$, 水面面积 $309.5 \mathrm{~km}^{2}$. 草海部分库容较小, 是目前昆明市主城区生活污水的主要受纳水体,每年平均换水 4-5 次; 而外 海面积广阔, 库容较大, 由于滇池流域集水面积相对较小, 同时一部分污水经由草海的西园遂道外排, 因此 水量交换时间较长, 换水时间约为 $2-5 \mathrm{a}^{[5]}$. 一般情况下,滇池草海和外海水体互不交换.

2004 年以来, 滇池草海始终保持劣 $V$ 类水质, 主要污染因子为总氮 $(T N)$ 、总磷 $(T P)$, 氨氮 $\left(\mathrm{NH}_{3}-\mathrm{N}\right)$ 浓度 也居高不下. 2006 年后, 外海水质也退化为劣 V 类, 主要污染因子为 TN、TP. 从水质来看, 滇池草海和外海水 质仍呈持续恶化的趋势. 从富营养化指数来看, 草海和外海的富营养化程度在 6 年间变化不大, 草海始终维 持在重度富营养化水平, 外海处于中度富营养化水平 ${ }^{[6]}$.

\section{2 研究方法}

采用水质模型和路径分析相结合的 方法,研究滇池流域“十二五”期间的污 染控制措施. 首先采用水质模型建立污 染负荷与水质之间的响应关系, 并根据 滇池水质目标,计算滇池流域污染物的 最大允许排放量和削减量; 然后采用路 径分析方法, 设计不同的污染物削减路 径, 获取能满足污染物削减目标的路径 组合方案; 最后, 综合考虑滇池流域污染 治理的可行性和经济性等因素, 确定最 终的污染控制方案.

由于滇池草海和外海水体混合相对 比较均匀, 因此采用零维模型进行容量 表 1 滇池污染物降解系数

Tab. 1 Degradation coefficients of the pollutants in Lake Dianchi

\begin{tabular}{lrrrr}
\hline 水体 项 目 & $\mathrm{COD}_{\mathrm{Cr}}$ & $\mathrm{NH}_{3}-\mathrm{N}$ & \multicolumn{1}{c}{$\mathrm{TN}$} & \multicolumn{1}{c}{$\mathrm{TP}$} \\
\hline 草海 人湖负荷 $(\mathrm{t} / \mathrm{a})$ & 9695.22 & 1988.86 & 3871.83 & 305.22 \\
污染物浓度 $(\mathrm{mg} / \mathrm{L})$ & 13.49 & 11.69 & 15.34 & 1.24 \\
出湖负荷 $(\mathrm{t} / \mathrm{a})$ & 722.66 & 626.15 & 821.72 & 66.58 \\
降解负荷 $(\mathrm{t} / \mathrm{a})$ & 8972.56 & 1362.71 & 3050.11 & 238.64 \\
降解系数 $(1 / \mathrm{a})$ & 10.54 & 6.61 & 11.27 & 10.88 \\
外海 人湖负荷 $(\mathrm{t} / \mathrm{a})$ & 15464.71 & 1686.14 & 7440.06 & 430.22 \\
污染物浓度 $(\mathrm{mg} / \mathrm{L})$ & 12.70 & 0.30 & 2.44 & 0.13 \\
出湖负荷 $(\mathrm{t} / \mathrm{a})$ & 2345.94 & 55.93 & 451.35 & 23.21 \\
降解负荷 $(\mathrm{t} / \mathrm{a})$ & 13118.77 & 1630.21 & 6988.71 & 407.01 \\
降解系数 $(\mathrm{L} / \mathrm{a})$ & 0.19 & 4.53 & 2.41 & 2.73 \\
\hline
\end{tabular}
核算,其表达式为 ${ }^{[7]}$ :

$$
V \frac{\mathrm{d} C}{\mathrm{~d} t}=Q C_{0}-q C-k V C
$$

式中, $C$ 为湖体的污染物平均浓度 $(\mathrm{mg} / \mathrm{L}) ; Q$ 为人湖水量 $\left(\mathrm{m}^{3} / \mathrm{s}\right) ; C_{0}$ 为人湖污染物浓度 $(\mathrm{mg} / \mathrm{L}) ; q$ 为出湖水 量 $\left(\mathrm{m}^{3} / \mathrm{s}\right) ; k$ 为污染物降解系数 $(\mathrm{L} / \mathrm{s}) ; V$ 为库容 $\left(\mathrm{m}^{3}\right) ; t$ 为时间 $(\mathrm{s})$.

稳态条件下, 污染物的浓度保持不变, 因此:

$$
V \frac{\mathrm{d} C}{\mathrm{~d} t}=Q C_{0}-q C-k V C=0
$$


从而有:

$$
C=\frac{Q C_{0}}{q+k V}
$$

以 2008 年滇池草海和外海的污染物入湖量和湖体污染物平均浓度进行模型校验, 可得到草海和外海 的污染物降解系数 (表 1 ).

\section{2 总量削减方案和目标}

\section{1 总量计算设计条件}

根据昆明市水利勘测设计院《利用西园隧洞优化调度滇池弃水改善滇池水质方案研究》中 40 年长系列 计算成果和昆明市水环境容量测算的研究成果, 滇池草海和外海所采用的设计水文条件为 $80 \%$ 保证率(枯 水年) 水量平衡条件 (表 2). 牛栏江一滇池补水工程是滇池流域 “十一五” 水污染防治规划的重点工程, 工程 项目于 2008 年启动, 预计 2012 年建成. 工程建设的目标是引水 $6 \times 10^{8} \mathrm{~m}^{3}$, 调水水质规划为湖库 III 类.

表 2 滇池容量计算的设计水文条件 $\left(\times 10^{4} \mathrm{~m}^{3}\right)^{*}$

Tab. 2 Hydrological design condition of Lake Dianchi for environment capacity calculation

\begin{tabular}{rcccccrrr}
\hline 水体 & 年型 & $Q_{\text {进 }}$ & $Q_{\text {交 }}$ & $Q_{\text {蒸 }}$ & $Q_{\text {工 }}$ & $Q_{\text {农 }}$ & $Q_{\text {出 }}$ & $D_{V}$ \\
\hline 草海 & $P=80 \%$ & 12358 & 0 & 983 & 4504 & 1630 & 5357 & -115 \\
外海 & $P=80 \%$ & 56812 & 0 & 39566 & 5830 & 10095 & 18472 & -17151 \\
\hline
\end{tabular}

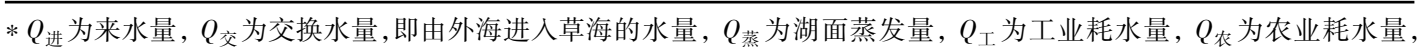

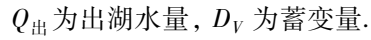

\section{2 污染防治方案设计}

预期水质目标包括三个方案, 即高方案、中方案和低方案 (表 3 ). 高方案为草海达到 $\mathrm{V}$ 类水, 外海达到 IV 类水; 低方案为滇池水质恶化的趋势得以遏制, 并在 2008 年基础上略有改进, 草海和外海 TN 和 TP 的 浓度较 2008 年下降约 10\% ; 中方案则是滇池水质在 2008 年基础上有明显改善, 是高方案和低方案的折 中方案, 也就是说确保实现 2015 年的阶段目标, 以最终实现 2020 年草海达到 V 类水、外海达到 IV 类水的 目标.

表 3 滇池水质目标方案设计 $(\mathrm{mg} / \mathrm{L})$

Tab. 3 Scenarios of water quality objectives in Lake Dianchi $(\mathrm{mg} / \mathrm{L})$

\begin{tabular}{cccrrc}
\hline 方案 & 区域 & $\mathrm{COD}_{\mathrm{Mn}}$ & $\mathrm{NH}_{3}-\mathrm{N}$ & $\mathrm{TN}$ & $\mathrm{TP}$ \\
\hline \multirow{2}{*}{2008 年 } & 草海 & 13.5 & 11.7 & 15.3 & 1.20 \\
& 外海 & 12.7 & 0.3 & 2.4 & 0.10 \\
高方案 & 草海 & 12.0 & 2.0 & 2.0 & 0.20 \\
& 外海 & 10.0 & 0.3 & 1.5 & 0.10 \\
中方案 & 草海 & 12.0 & 6.0 & 8.5 & 0.60 \\
& 外海 & 10.0 & 0.3 & 2.0 & 0.11 \\
低方案 & 草海 & 12.0 & 10.0 & 15.0 & 1.00 \\
& 外海 & 10.0 & 0.3 & 2.2 & 0.12 \\
\hline
\end{tabular}

表 4 扣除牛栏江一滇池补水工程引水负荷后的 最大允许排放量 $(\mathrm{t} / \mathrm{a})$

Tab. 4 Total allowable discharge load excluding Niulanjiang-Dianchi Water Transfer Project input(t/a)

\begin{tabular}{ccrrrr}
\hline 区域 & 指标 & $\mathrm{COD}_{\mathrm{Cr}}$ & $\mathrm{NH}_{3}-\mathrm{N}$ & $\mathrm{TN}$ & $\mathrm{TP}$ \\
\hline 滇池总体 & 高方案 & 27161 & 1693 & 5402 & 427 \\
& 中方案 & 27161 & 2614 & 9225 & 589 \\
& 低方案 & 27161 & 3534 & 11973 & 751 \\
滇池草海 & 高方案 & 9584 & 400 & 565 & 58 \\
& 中方案 & 9584 & 1321 & 2596 & 180 \\
& 低方案 & 9584 & 2242 & 4626 & 303 \\
滇池外海 & 高方案 & 17577 & 1293 & 4837 & 369 \\
& 中方案 & 17577 & 1293 & 6630 & 409 \\
& 低方案 & 17577 & 1293 & 7347 & 449 \\
\hline & & & & &
\end{tabular}

\section{3 污染物最大允许排放量}

对应不同的水质目标方案, 滇池流域的最大允许排放量具有明显差异 (表 4). 因此, 为达到保护滇池水 质的目标, 应以总量控制为手段, 严格控制入湖污染负荷. 查阅相关文献, 对比本研究滇池流域最大允许排 
放量与其它文献的计算结果, 发现各次最大允许排放量计算的水质目标之间均有一定的差异 (表 5 ). 根据不 同方案条件下滇池最大允许排放量的要求,以及 2015 年污染物人湖量不得超过 2008 年基准年的要求,确定 滇池污染物负荷削减目标 (表 6 ).

表 5 “十二五规划”最大允许排放量与其它研究成果的对比 *

Tab. 5 Comparison of the total allowable load with other research results

\begin{tabular}{|c|c|c|c|c|c|c|c|c|c|}
\hline \multirow{2}{*}{ 区域 } & \multirow{2}{*}{ 数据来源 } & \multicolumn{4}{|c|}{ 最大允许排放量(t/a) } & \multicolumn{4}{|c|}{ 水质目标 $(\mathrm{mg} / \mathrm{L})$} \\
\hline & & $\mathrm{COD}_{\mathrm{Cr}}$ & $\mathrm{NH}_{3}-\mathrm{N}$ & $\mathrm{TN}$ & $\mathrm{TP}$ & $\mathrm{COD}_{\mathrm{Cr}}$ & $\mathrm{NH}_{3}-\mathrm{N}$ & $\mathrm{TN}$ & $\mathrm{TP}$ \\
\hline \multirow[t]{6}{*}{ 草海 } & 杨龙文, $2002^{[8]}$ & 14606 & - & 360 & 27 & 10 & 1.5 & 1.5 & 0.10 \\
\hline & 吴为梁, $1993^{[9]}$ & 4300 & - & 568 & 57 & 10 & - & 2.0 & 0.20 \\
\hline & 全国环境容量核算,2004 & 11523 & - & 675 & 28 & 10 & 1.5 & 1.5 & 0.10 \\
\hline & 滇池生态安全保障方案,2009 & 19122 & - & 574 & 57 & 15 & 2.0 & 2.0 & 0.20 \\
\hline & “十二五”规划,2010 & 7187 & 255 & 379 & 25 & 10 & 1.5 & 1.5 & 0.10 \\
\hline & “十二五”规划,2010 & 10780 & 340 & 505 & 49 & 15 & 2.0 & 2.0 & 0.20 \\
\hline \multirow[t]{6}{*}{ 外海 } & 杨龙文, $2002^{[8]}$ & 27958 & - & 1095 & 97 & 6 & 1.0 & 1.0 & 0.05 \\
\hline & 吴为梁, $1993^{[9]}$ & 6927 & - & 2194 & 183 & 4 & - & 0.6 & 0.05 \\
\hline & 全国环境容量核算,2004 & 17710 & - & 4145 & 226 & 6 & 1.0 & 1.0 & 0.05 \\
\hline & 滇池生态安全保障方案,2009 & 33195 & - & 4078 & 321 & 10 & 1.5 & 1.5 & 0.10 \\
\hline & “十二五”规划,2010 & 12177 & 8354 & 4567 & 342 & 10 & 1.5 & 1.5 & 0.10 \\
\hline & “十二五”规划,2010 & 14499 & 5825 & 3425 & 196 & 6 & 1.0 & 1.0 & 0.05 \\
\hline
\end{tabular}

* 全国水环境容量核算结果为 2004 年滇池数据; 杨龙文和吴为梁为 $\mathrm{COD}_{\mathrm{Mn}}$ 的数据.

表 6 滇池流域污染物负荷削减目标 $(\mathrm{t} / \mathrm{a})$

Tab. 6 Waste Load cut task in Lake Dianchi Catchment(t/a)

\begin{tabular}{|c|c|c|c|c|c|c|}
\hline 类型 & 区域 & 类型 & $\mathrm{COD}_{\mathrm{Cr}}$ & $\mathrm{NH}_{3}-\mathrm{N}$ & $\mathrm{TN}$ & $\mathrm{TP}$ \\
\hline \multirow[t]{2}{*}{2015 年预测产生量 } & & 草海 & 44319 & 4712 & 7113 & 618 \\
\hline & & 外海 & 69435 & 6837 & 12414 & 1171 \\
\hline \multirow[t]{2}{*}{ 现有的削减能力 } & & 草海 & 19507 & 1522 & 1433 & 177 \\
\hline & & 外海 & 38355 & 3470 & 3197 & 633 \\
\hline \multirow[t]{9}{*}{ 新增削减需求 } & 滇池流域 & 高方案 & 33235 & 4864 & 9495 & 551 \\
\hline & & 中方案 & 33235 & 3943 & 5672 & 389 \\
\hline & & 低方案 & 33235 & 3023 & 2924 & 227 \\
\hline & 草海 & 高方案 & 16817 & 2790 & 5115 & 383 \\
\hline & & 中方案 & 16817 & 1869 & 3085 & 261 \\
\hline & & 低方案 & 16817 & 948 & 1054 & 138 \\
\hline & 外海 & 高方案 & 16418 & 2074 & 4379 & 168 \\
\hline & & 中方案 & 16418 & 2074 & 2587 & 128 \\
\hline & & 低方案 & 16418 & 2074 & 1870 & 89 \\
\hline
\end{tabular}




\section{3 削减备选路径及评估}

\section{1 备选路径及参数}

根据草海和外海不同的区域特点, 提出污染物的备选削减路径. 以实现预期的削减量目标, 进行路径优 选,并最终确定流域污染治理路径.

草海和外海区域进行污染源削减的主要措施包括提高牛栏江一滇池补水工程的人湖水质、提高城镇污 水收集和处理率、进行污水处理厂深度处理、污水处理厂出水排放到滇池流域外或用于浇灌、农业面源治理 和湿地处理 (表 7).

表 7 滇池流域主要削减措施

Tab. 7 List of the primary treatment countermeasures in Lake Dianchi Catchment

草海流域削减备选路径

外海流域削减备选路径

A. 提高牛栏江一滇池补水工程入湖水质
A1 人湖水质达到湖库 III 类水
A2 人湖水质达到湖库 II 类半水

B. 提高城镇生活污水收集率
B1 收集率提高到 $80 \%$
B2 收集率提高到 $90 \%$
B3 收集率提高到 $95 \%$

C. 污水处理厂深度处理方案
C1 出水浓度达到一级 A 标准
$\mathrm{C} 2$ 出水浓度达到地表水 $\mathrm{V}$ 类标准
C3 出水浓度达到地表水 IV 类标准

D. 污水处理厂尾水直排滇池流域外或用于浇灌
D1 尾水不外排或浇灌
D2 尾水 $10 \%$ 外排或浇灌
D3 尾水 $30 \%$ 外排或浇灌
D4 尾水 $50 \%$ 外排或浇灌
D5 尾水 $80 \%$ 外排或浇灌
D6 尾水 $100 \%$ 外排或浇灌

E. 农业面源治理
E1 维持现状
E2 面源削减 $20 \%$
E3 面源削减 30\%
E4 面源削减 $50 \%$
E5 面源削减 $80 \%$

A. 提高牛栏江一滇池补水工程人湖水质

A1 人湖水质达到湖库 III 类水

A2 人湖水质达到湖库 II 类半水

B. 提高城镇生活污水收集率
B1 收集率提高到 $80 \%$
B2 收集率提高到 $90 \%$

C. 污水处理厂深度处理方案
$\mathrm{C} 1$ 出水浓度达到一级 A 标准
$\mathrm{C} 2$ 出水浓度达到地表水 $\mathrm{V}$ 类标准
C3 出水浓度达到地表水 IV 类标准

D. 污水处理厂尾水直排滇池流域外或用于浇灌
D1 尾水不外排或浇灌
D2 尾水 $10 \%$ 外排或浇灌
D3 尾水 $20 \%$ 外排或浇灌
D4 尾水 $30 \%$ 外排或浇灌
D5 尾水 $50 \%$ 外排或浇灌
D6 尾水 $80 \%$ 外排或浇灌

E. 农业面源治理
E1 维持现状
E2 面源削减 $10 \%$
E3 面源削减 20\%
E4 面源削减 30\%

F. 湿地处理

F1 全部为自然湿地

\section{2 路径优选与评估}

路径优选主要遵循以下几个原则: 首先, 优选的路径必须能够满足削减目标的要求; 其次, 判断路径是 否帕累托非劣解, 也就是说, 如果两个路径都能够满足削减量的要求, 而另一个路径在各方面的削减强度都 要大于前一个路径, 则该路径不是帕累托非劣解, 应予排除 ${ }^{[10]}$; 最后, 结合路径的可行性最终确定最佳路径.

高方案草海共有 30 个路径组合能够满足削减目标, 其中帕累托非劣解为 7 个. 考虑到现状出水浓度与 地表水 $\mathrm{V}$ 类标准和 $\mathrm{V}$ 类标准的差异比较大, 因此只考虑污水处理厂出水浓度一级 $\mathrm{A}$ 标的路径. 考虑到技术 经济可行性, 推荐路径组合 A1 + B3 + C1 + D6 + E3 为最佳路径. 外海共有 56 个路径组合能够满足高方案的 
削减目标, 其中帕累托非劣解为 7 个. 只考虑污水处理厂出水一级 A 标的路径, 推荐路径组 $\mathrm{A} 1+\mathrm{B} 2+\mathrm{C} 1+$ $\mathrm{D} 6+\mathrm{E} 3+\mathrm{F} 1$ 为最佳路径.

中方案草海共有 410 个路径组合能够满足削减目标, 其中帕累托非劣解为 7 个. 只考虑污水处理厂出水 浓度一级 $\mathrm{A}$ 标的路径,推荐路径组合 $\mathrm{A} 1+\mathrm{B} 2+\mathrm{C} 1+\mathrm{D} 2+\mathrm{E} 1$ 为最佳路径. 外海共有 91 个路径组合能够满足 高路径的削减目标, 其中帕累托非劣解为 7 个. 只考虑污水处理厂出水一级 $\mathrm{A}$ 标的路径, 推荐路径组 $\mathrm{A} 1+$ $\mathrm{B} 2+\mathrm{C} 1+\mathrm{D} 6+\mathrm{E} 2+\mathrm{F} 1$ 为最佳路径.

低方案草海共有 415 个路径组合能够满足削减目标, 其中帕累托非劣解为 3 个. 只考虑污水处理厂出水 浓度一级 $\mathrm{A}$ 标的路径,推荐路径组合 $\mathrm{A} 1+\mathrm{B} 2+\mathrm{C} 1+\mathrm{D} 1+\mathrm{E} 1$ 为最佳路径. 外海共有 115 个路径组合能够满 足高方案的削减目标, 其中帕累托非劣解为 3 个. 只考虑污水处理厂出水一级 $\mathrm{A}$ 标的路径, 推荐路径组合 $\mathrm{A} 1+\mathrm{B} 2+\mathrm{C} 1+\mathrm{D} 5+\mathrm{E} 1+\mathrm{F} 1$ 为最佳路径. 根据高、中、低三种方案最佳路径评估结果, 三种方案的削减路径 比较见图 1 和图 2.

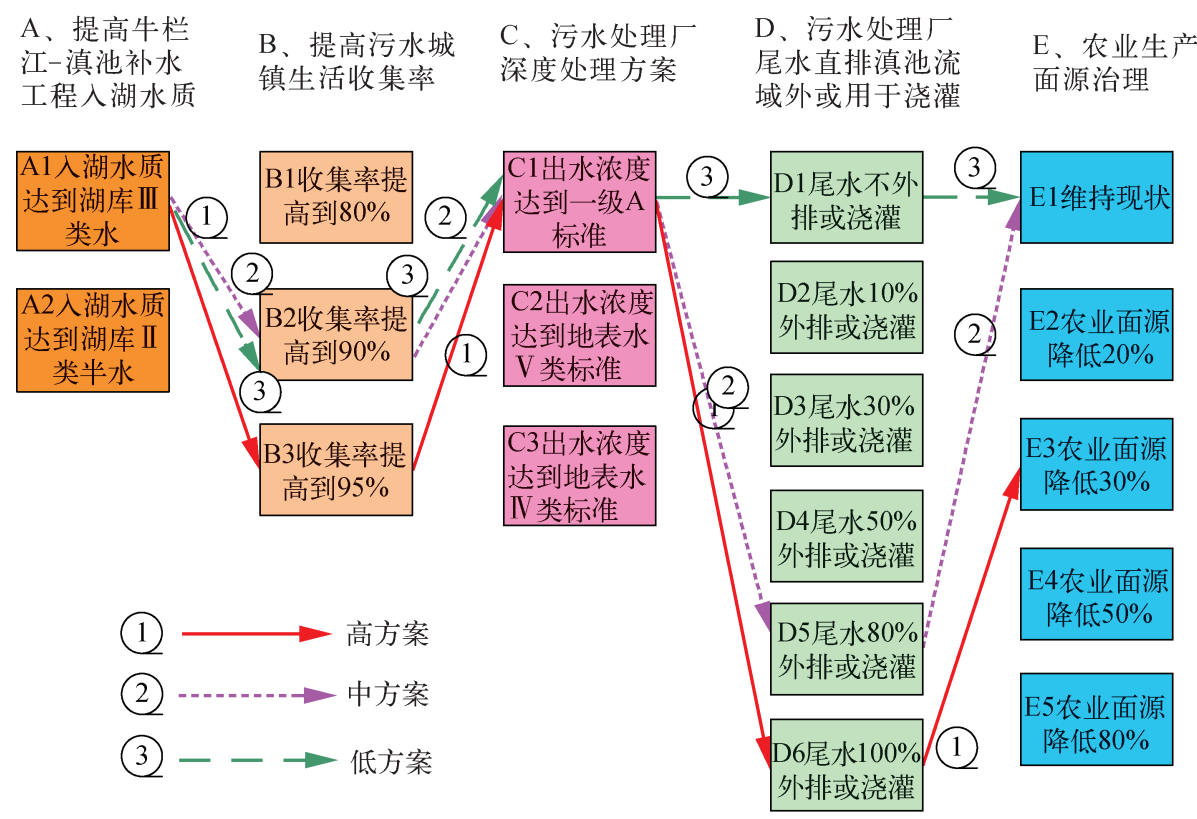

图 1 草海不同水质目标方案条件下的最佳削减路径比较

Fig. 1 The best cut routes under different water quality scenarios in Caohai Catchment

\section{4 方案建议}

考虑到高方案要求草海流域城镇生活污水收集率达到 $95 \%$,污水处理厂出水 $100 \%$ 外排或浇灌,外海流 域农业面源削减相对比较困难等因素，同时吸取“九五”、“十五”和“十一五”期间因水质目标订得过高而都 未能实现预定目标的教训,因此不推荐高方案. 中方案在低方案的基础上,仅提高污水处理厂出水外排率就 能达到,因此推荐中方案为“十二五”期末的水质目标方案.

因此,草海 $\mathrm{COD}_{\mathrm{Mn}} 、 \mathrm{NH}_{3}-\mathrm{N} 、 \mathrm{TN}$ 和 TP 的水质目标分别为 $12 、 6 、 9 、 0.6 \mathrm{mg} / \mathrm{L}$, 在 2008 年的基础上分别下降 $11 \% 、 49 \% 、 45 \%$ 和 $52 \%$. 相应的推荐治理措施为: 牛栏江一滇池补水工程人湖水质达到湖库正类水质标准, 城市污水收集率达到 $90 \%$, 污水处理厂出水达一级 $\mathrm{A}$ 标,第一、第三和第九污水处理厂尾水共 $1.3 \times 10^{8} \mathrm{~m}^{3}$ 排 放到滇池流域外或进行浇灌等可去除污染物的中水回用. 外海 $\mathrm{COD}_{\mathrm{Mn}} 、 \mathrm{NH}_{3}-\mathrm{N} 、 \mathrm{TN}$ 和 TP 的水质目标分别为 $10 、 0.3 、 2 、 0.11 \mathrm{mg} / \mathrm{L}$, 在 2008 年的基础上分别下降 $21 \% 、 0 \% 、 18 \%$ 和 $12 \%$. 相应的推荐治理措施为: 牛栏 江一滇池补水工程人湖水质达到湖库 III 类水质标准,城市污水收集率达到 $90 \%$, 污水处理厂出水达一级 A 
A、提高牛栏 江-滇池补水 工程入湖水质

B、提高污水城 镇生活收集率
C、污水处理厂 深度处理方案
D、污水处理厂 尾水直排滇池流 域外或用于浇灌
E、农业生产 面源治理

F、湿地处理

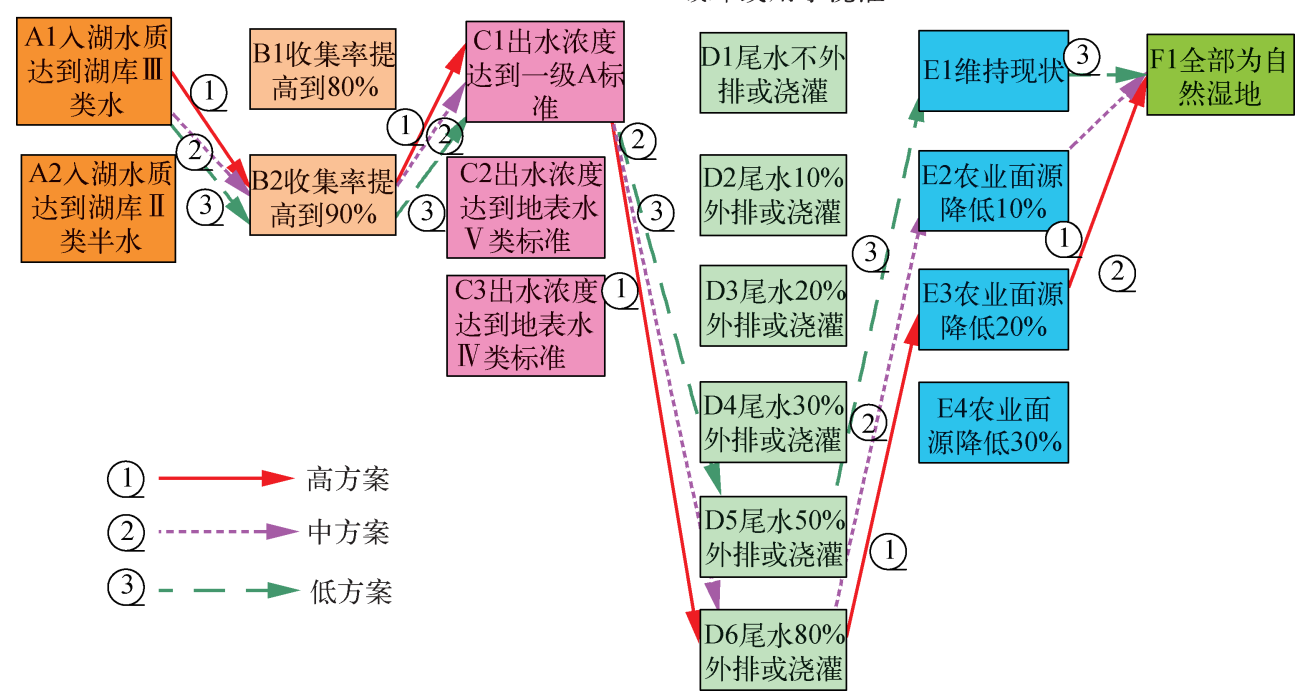

图 2 外海不同水质目标方案条件下的最佳削减路径比较

Fig. 2 The best cut routes under different water quality scenarios in Waihai Catchment

标, 第七、第八污水处理厂尾水共 $1.1 \times 10^{8} \mathrm{~m}^{3}$ 排放到滇池流域外或进行浇灌等可去除污染物的中水回用, 并 且农业面源去除率达到 $10 \%$.

为克服水质对污染负荷削减响应的迟滞效应, 草海和外海的污染控制方案应提前 1-2 年完成, 才能确 保“十二五”末实现规划的水质目标.

\section{5 参考文献}

[1 ] 孟 伟. 流域水污染总量控制技术与示范. 北京:中国环境科学出版社,2008:18-19.

[2] 徐永利. 苏州市化学需氧量总量控制研究 [学位论文].北京: 北京林业大学,2008:41-50.

[ 3 ] 陈六一,张 明,徐鹏炜. 浙江省太湖流域水环境管理思路研究. 环境污染与防治,2010,32(9):80-83.

[4]王宏, 孟凡宇, 邢 妍. 水环境承载力与污染物总量分配研究进展. 辽宁大学学报 (自然科学版), 2009,36 (4): 364-367.

[ 5] 刘玉生,郑丙辉,戴树桂等. 滇池富营养化及其综合治理技术研究. 北京: 海洋出版社, 2004:1-5.

[ 6 ] 李跌勋, 徐晓梅, 何 佳等. 滇池流域点源污染控制与存在问题解析. 湖泊科学,2010,22 (5):633-639.

[ 7 ] 傅国伟,程声通. 水污染控制系统规划. 北京:清华大学出版社, 1985:206-232.

[ 8 ] 杨文龙,杨常亮. 滇池水环境容量模型研究及容量计算结果. 云南环境科学, 2002,21 (3) :20-23.

[ 9 ] 吴为梁,张秀敏. 滇池水环境容量研究. 云南环境科学, 1993,12(1):6-8.

[10］张 燕, 张 洪. 以生态补偿实现水土资源开发的帕累托最优. 水土保持研究, 2010,17(4):109-113. 